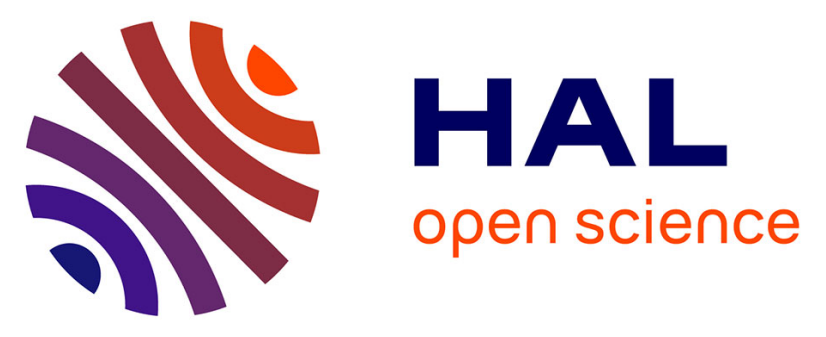

\title{
Observation of the Dynamics of Hydrothermal Activity in La Soufrière of Guadeloupe Volcano with Joint Muography, Gravimetry, Electrical Resistivity Tomography, Seismic and Temperature Monitoring
}

Dominique Gibert, Jean de Bremond d'Ars, B. Carlus, Sébastien Deroussi, Jean-Christophe Ianigro, David E Jessop, Kevin Jourde, Bruno Kergosien, Yves Le Gonidec, Nolwenn Lesparre, et al.

\section{- To cite this version:}

Dominique Gibert, Jean de Bremond d'Ars, B. Carlus, Sébastien Deroussi, Jean-Christophe Ianigro, et al.. Observation of the Dynamics of Hydrothermal Activity in La Soufrière of Guadeloupe Volcano with Joint Muography, Gravimetry, Electrical Resistivity Tomography, Seismic and Temperature Monitoring. László Oláh, Hiroyuki K. M,. Tanaka Dezsö Varga. Muography: Exploring Earth's Subsurface with Elementary Particles, 270, American Geophysical Union - Wiley, Chapter 5, 55-73, 2022, Geophysical Monograph Series, 9781119723028. 10.1002/9781119722748.ch5 . insu-03575607

\section{HAL Id: insu-03575607 https://hal-insu.archives-ouvertes.fr/insu-03575607}

Submitted on 21 Feb 2022

HAL is a multi-disciplinary open access archive for the deposit and dissemination of scientific research documents, whether they are published or not. The documents may come from teaching and research institutions in France or abroad, or from public or private research centers.
L'archive ouverte pluridisciplinaire HAL, est destinée au dépôt et à la diffusion de documents scientifiques de niveau recherche, publiés ou non, émanant des établissements d'enseignement et de recherche français ou étrangers, des laboratoires publics ou privés. 
Chapter 5

Observation of the Dynamics

of Hydrothermal Activity in

La Soufrière of Guadeloupe

solcano with Joint

- Muography, Gravimetry,

, Electrical Resistivity

- Tomography, Seismic and

- Temperature Monitoring

10 Dominique Gibert,,${ }^{1,2}$ Jean de Bremond d'Ars, ${ }^{3}$ Bruno

${ }_{11}$ Carlus, ${ }^{4} \mathrm{~S}^{\text {'ebastien Deroussi, }}{ }^{5,6}$ Jean-Christophe Ianigro, ${ }^{4}$ David E.

12 Jessop, ${ }^{5,6,7}$ Kevin Jourde, ${ }^{8}$ Bruno Kergosien, ${ }^{3}$ Yves Le

13 Gonidec, ${ }^{3}$ Nolwenn Lesparre, ${ }^{9}$ Jacques Marteau, ${ }^{4,10}$ Roberto

14 Moretti, $^{\mathbf{5}, 6}$ Florence Nicollin, $^{\mathbf{3}}$ and Marina Rosas-Carbajal ${ }^{\mathbf{5}}$

${ }^{15}{ }^{1}$ LGL-TPE, Univ Lyon, Univ Lyon 1, ENSL, CNRS, UMR 5276, 69622, Villeurbanne,

16 Géode Bldg, la Doua Campus, France

$17{ }^{2}$ National Volcano Observatory Service, Univ Lyon 1 Observatory, CNRS, UMS 3721,

18 69622, Villeurbanne, Géode Bldg, la Doua Campus, France

$19{ }^{3}$ Univ Rennes, CNRS, Géosciences Rennes - UMR 6118, F-35000, Rennes, France

$20{ }^{4}$ IP2I, Univ Lyon, Univ Claude Bernard Lyon 1, CNRS/IN2P3, UMR 5822, F-69622,

Villeurbanne, France

${ }^{5}$ Université de Paris, Institut de Physique du Globe de Paris, UMR 7154 CNRS, F-75005,

Paris, France 
so 1.1. Objectives plosive events. toring, fumerole temperature

Muography uses muons contained in the natural cosmic rays to determine the density of rock volumes. The measurements consist in counting the muons emerging from the target to determine the screening effect produced by the rock. Because the larger the rock thickness, the smaller the number of muons able to cross, the time resolution that can be achieved by muography to monitor density changes is on the order of one or two weeks for kilometer-sized volcanoes. This limitation of the method can be reduced by joining muography with high time-resolution measurements like passive seismic monitoring. In the case of structural imaging, muography benefits from the fact that muon trajectories are linear, making the tomography problem simpler than for other geophysical techniques like electrical resistivity tomography. Experiments performed on La Soufrière of Guadeloupe volcano are described to show how muography can be used to contribute to structural imaging of an highly heterogeneous lava dome and to detect abrupt transient hydrothermal phenomena likely to produce dangerous ex-

Keywords: volcanic hydrothermal systems, muon tomography, geophysical methods, gravimetry, electrical resistivity tomography, seismic moni-

51 - Present the interest of hydrothermal systems monitoring

52 - Discuss the characteristics of muography for hydrothermal systems monitoring

- Present the various geophysical experiments performed on La Soufrière of Guadeloupe

56 - Discuss the results and propose a model of hydrothermal phenomena 


\subsection{Introduction}

A significant amount of applications that made muography popular during the last decade concern volcanoes [Tanaka et al., 2007, 2009a,b, 2010, Gibert et al., 2010, Lesparre et al., 2011, Carbone et al., 2014, Jourde et al., 2016a]. Actually, muography possesses several key advantages for volcano imaging: i) the possibility to radiography the emerging part of the volcano from a single remote viewpoint allows to study active dangerous unapproachable volcanoes; ii) high density contrasts are often present in volcanoes, making muography particularly relevant; iii) the fact that muon trajectories may be considered linear makes the tomography inverse problem simpler; iv) continuous measurements offer the possibility to monitor density changes caused by either hydrothermal phenomena and lava ascent.

Among the many phenomena observed on volcanoes, phreatic and hydrothermal explosions in volcanic geothermal fields [Rouwet et al., 2014, ErfurtCooper, 2017] are subject to a growing attention in response to the occurrence of the recent laterally-directed explosions that caused at least 58 fatalities at Ontake volcano (Japan) in 2014 [Kaneko et al., 2016]. Other eruptions occurred in New Zealand at the Te Maari Crater in Mount Tongariro (2012) [Jolly et al., 2014] and in Whakaari/White Island (2019) [Dempsey et al., 2020]. Presently, these catastrophic events are considered unpredictable [Kaneko et al., 2016], and identifying precursors of unrest in shallow hydrothermal systems [Tonini et al., 2016] is made difficult because of the specificity of each volcanic system [Phillipson et al., 2013]. Detecting transient early warning signals of imminent destabilization [Sano et al., 2015, Oikawa et al., 2016] among the many signals produced by the long-standing activity of well-developed hydrothermal systems constitutes a formidable challenge. Muography can significantly contribute to make progress by bringing spatial and temporal information about the parts of shallow hydrothermal system that may destabilize.

In this chapter, we present a series of long-term experiments conducted on the La Soufrière volcano in Guadeloupe to document the detection of very short-term warning signals (i.e. time scales of hours and days) of possible hydrothermal destabilization in an active lava dome of moderate activity. La Soufrière is one of a few volcanoes very well suited for this kind of study [Boudon et al., 2007, 2008]. Its moderate activity allows safe field work but is sufficient to produce internal density variation that could be detected with various methods and especially muography. The dome being less than $1 \mathrm{~km}$ wide, it can be crossed by enough cosmic muons to give pertinent images of its internal structure. The size scale of the internal heterogeneities is on the order of a few meters to a few tens of meters so they are large enough to be detected. Since the last 1976-1977 eruption, considered as a failed magmatic event [Feuillard et al., 1983, Villemant et al., 2014], degassing first decreased to 


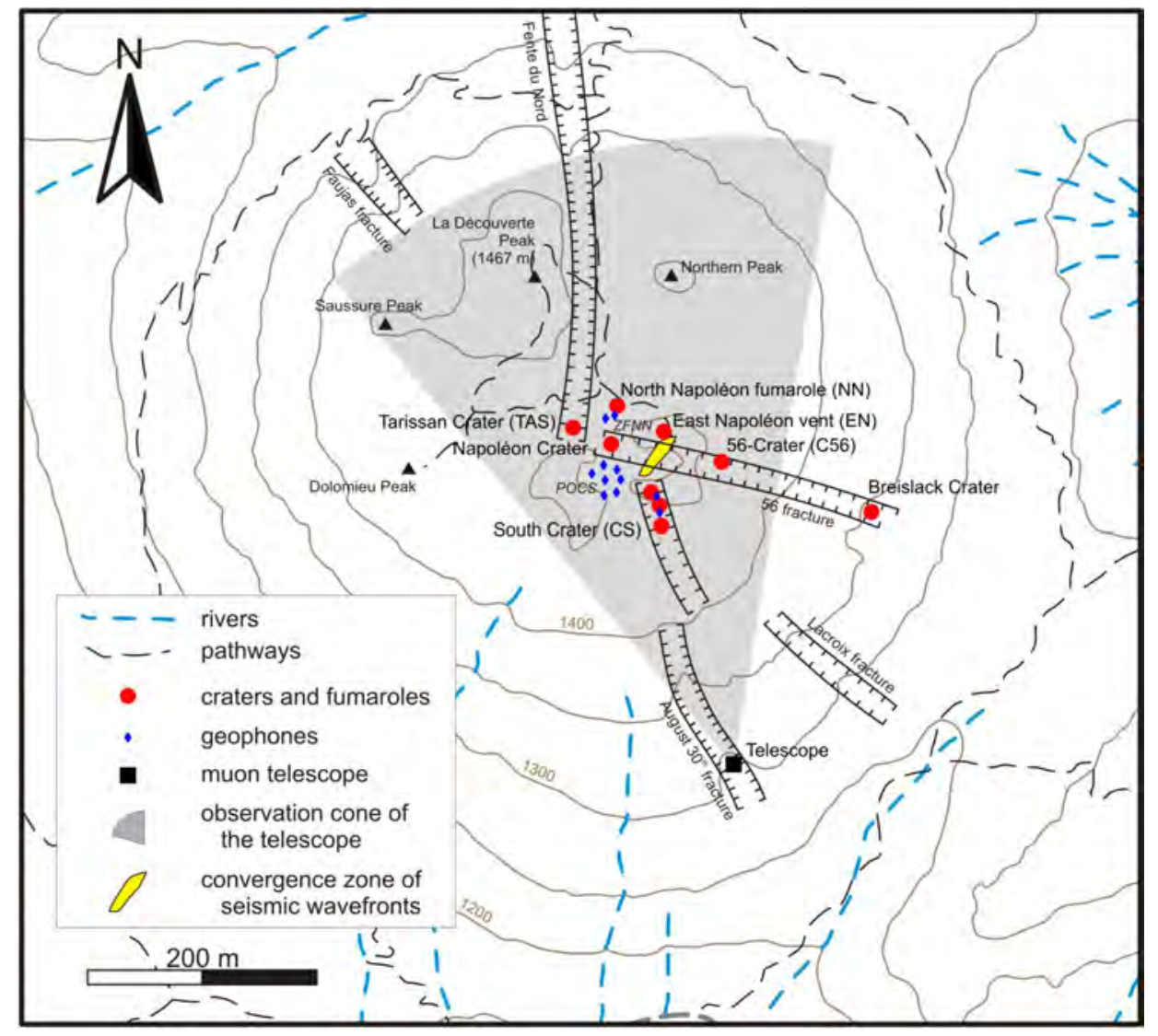

Figure 1.1: Main structures of the La Soufrière lava dome with sensor emplacements. The gray sector represents the view field of the muon telescope (black square) placed in the 30 August fracture at its apex. Vents are shown as red dots, geophones as blue diamonds, and the yellow patch is the plan view of the source of seismic noise (see Fig. 1.9). Reprinted from Le Gonidec et al. [2019]. 
a minimum in 1991 before increasing again with an intense fumarolic activity at the summit since 1992 in the South Crater vents area (Fig. 1.1). Since 2014, new active regions appeared to the East of the Tarissan and Dupuy craters (Fig. 1.1) perhaps due to flow paths rearrangement caused by the progressive sealing of open fractures [Rosas-Carbajal et al., 2016]. This hydrothermal activity is compatible with an increasingly vapor-dominated system favorable to local destabilization. At least two small explosions occurred in 2016 in the EastNapoléon vent (Fig. 1.1) and an accelerated episode of unrest was observed during April 2018, which resulted from increased heating and pressurization of the hydrothermal system and a quick (order of days) excursion through the critical point of water [Moretti et al., 2020]. Such hazardous environments result from rapid phenomena occurring inside the lava dome at time scales of few hours or days.

\subsection{Muography for volcano applications}

We recall the muography characteristics either particularly relevant or specific to volcano applications and, particularly, the monitoring of shallow hydrothermal systems. More detailed description of the muography method are given in other chapters of this book.

The main concerns encountered when applying muography to the monitoring of hydrothermal systems are:

- The resolution that can be achieved for density, space and time and results from a trade off among these three quantities.

- The perturbing effects likely to corrupt the data.

- The practical difficulties encountered during field implementation and maintenance of the equipment.

These items are discussed in the next three sections.

\subsubsection{Field implementation and maintenance}

Volcanoes often constitute harsh environments where various aggressive or difficult conditions make the installations of the telescopes and their long-term operation problematic. On tropical volcanoes like La Soufrière, the main problems come from tropical storms, heavy rains, lightning, and acidic gas emissions, mainly from steam-rich fumaroles. On a volcano like Mount Etna, additional difficulties come from snow and ash falls that may destroy the equipment. Beside these problems due to natural environment, rough installation conditions must be accounted for: strong shocks during transportation either by 


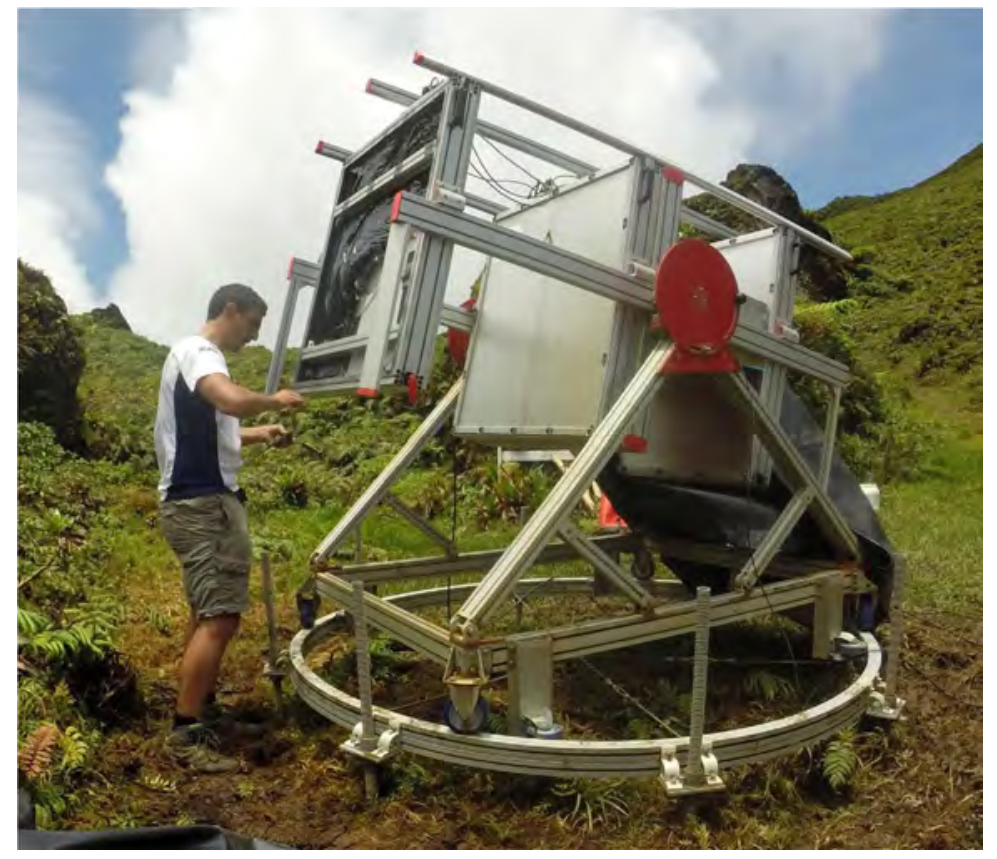

Figure 1.2: View of a field telescope in maintenance on La Soufrière at the Rocher Fendu location. The instrument counts 3 detection matrices (grey frames). A wall of lead bricks with a thickness of $5 \mathrm{~cm}$ is placed in front of the central detector. The telescope may easily be rotated to change both its azimuth and its inclination. When in operation, a tarpaulin covers the instruments to protect it against rain. Reprinted from Jourde et al. [2016b]. 
helicopter or by car, use of rope-access techniques. For these reasons, our telescopes are modular and rugged enough to support shocks and rain (Fig. 1.2). Electrical power units are necessary to make the telescope autonomous. On volcanoes like La Soufrière, poor weather conditions render photo-voltaic units poorly efficient and approximately $10 \mathrm{~W}$ of photo-voltaic power are needed for $1 \mathrm{~W}$ of electrical power available 24 hours a day. These constrains prevent the use of large high-acceptance telescopes. The installation of WiFi links is necessary to both download the data and perform remote-control operations of the telescopes (e.g. reboot, change thresholds and coincidence criteria of on-board computers, etc.).

Another concern to consider during field implementation is the presence of secondary topography (e.g. other volcanoes, cliffs, etc.) behind the volcano of interest. Beside the fact that secondary topography reduces the flux of muons available to tomography the target, the effects of such secondary structures may be complicated to suppress when processing the data.

\subsubsection{Resolution in density, time, and space}

Muography shares the same principles than classical X-ray medical radiography, and consists in measuring the screening effect of a body of matter on an incident flux, $\Phi_{0}$, of cosmic muons. The loss of energy of the muons along their trajectories through rock results from bremsstrahlung, nuclear interactions, and $e^{+} e^{-}$pair production physical processes. Assuming that muons continuously loss their energy along along their way, the rate of energy loss may be written as (see e.g. Sokalski et al. [2001] for more details),

$$
-\frac{\partial E}{\partial \varrho}\left[\mathrm{MeV} \cdot \mathrm{cm}^{2} \cdot \mathrm{g}^{-1}\right]=a(E)+b(E) \cdot E,
$$

where the functions $a$ and $b$ depend on the material properties, mainly the atomic weight [Nagamine, 2003, Lesparre et al., 2011]. The flux, $\Phi_{E}$, of emerging muons is the part of the incident muons with an initial energy larger than the cut-off energy, $E_{\min }(\varrho)$, necessary to cross the opacity $\varrho\left[\mathrm{kg} \cdot \mathrm{m}^{-2}\right]=$ $\int_{\mathcal{L}} \rho(x) \mathrm{d} x$, where $\rho\left[\mathrm{kg} \cdot \mathrm{m}^{-3}\right]$ is the density distribution along the trajectory, $\mathcal{L}$, of the particle. Telescopes are designed to collect the flux of muons coming from a collection of trajectories (or lines of sight), $\left\{\mathcal{L}_{k}, k=1, \cdots, M\right\}$ which may be considered as straight lines excepted for low-energy muons or very dense matter (e.g. $\mathrm{Pb}, \mathrm{U}, \mathrm{W})$ where scattering may be non-negligible [e.g. Gómez et al., 2017]. Each line of sight is characterized by a solid angle and a detection area whose product is called the acceptance $\mathcal{T}\left[\mathrm{sr}_{\mathrm{cm}} \mathrm{cm}^{2}\right.$.

As a rule of thumb, a muon loses about $2.2 \mathrm{MeV}$ when crossing $1 \mathrm{~cm}$ of water [Scheck, 1978] (i.e. $-\mathrm{d} E / \mathrm{d} \rho=2.2 \mathrm{MeV} / \mathrm{g} / \mathrm{cm}^{2}$ ). A simple propor- 


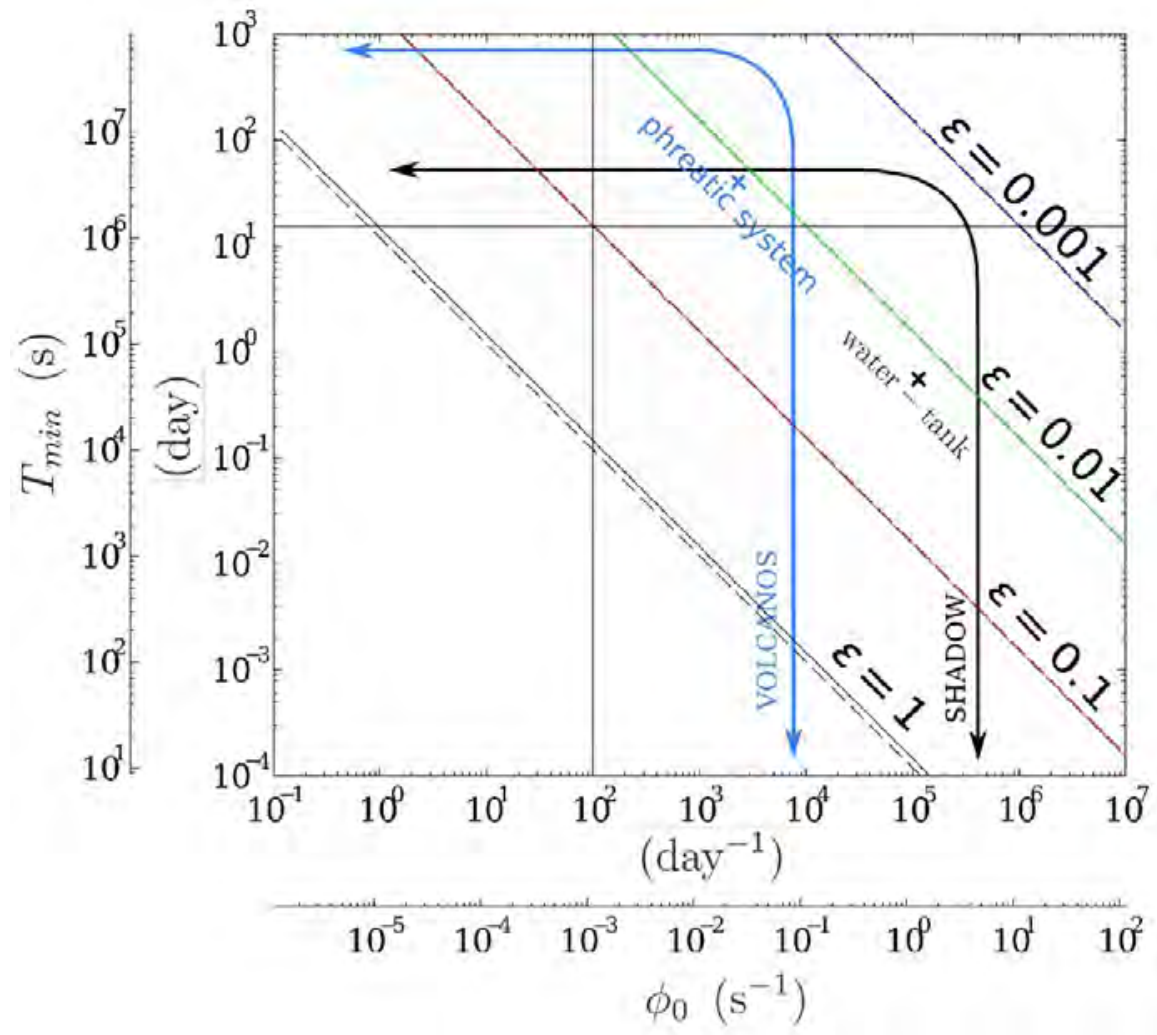

Figure 1.3: Minimum acquisition time $T_{\min }$ versus the average measured flux $\Phi_{0}$ necessary to detect a relative flux variation of $\varepsilon$ with a $95 \%$ confidence level. The blue curve delimits the resolution domain for typical volcano applications. Adapted from Jourde et al. [2016a]. 
tionality rule may be used to get a good estimate for other materials and trajectory lengths. For instance, to cross the atmosphere whose weight per surface unit equals $10 \mathrm{~m}$ of water, a muon loses about $E_{\min }=2.2 \mathrm{MeV} \cdot \mathrm{cm}^{-1} \times$ $10^{3} \mathrm{~cm}=2.2 \mathrm{GeV}$. For La Soufrière of Guadeloupe, taking an average density $\rho=2$ g.cm ${ }^{-3}$ (i.e. value for highly altered andesite lava blocks in Navelot et al. [2018]) and typical trajectory lengths of $500 \mathrm{~m}$, we obtain $E_{\min }=$ $2.2 \mathrm{MeV} \cdot \mathrm{cm}^{-1} \mathrm{~m}^{3} \mathrm{~kg}^{-1} \times 5 \times 10^{4} \mathrm{~cm} \times 2 \mathrm{~kg} \cdot \mathrm{m}^{-3}=220 \mathrm{GeV}$.

Such a value for $E_{\min }$ places the energy cut-off in the steep power-law part of the energy spectrum of cosmic muons [Gaisser et al., 2016], and only a tiny fraction of the incident muons will be able to cross the volcano to be detected by the telescope. Consequently, in volcano applications, the number of muons detected for a given trajectory is typically of the order of some tens per day or even less, depending on the thickness of rock. Signal-to-noise ratio then becomes a issue of critical importance, particularly in monitoring experiments where density time-changes are to be detected. To illustrate this problem, let us consider the case of a sudden opacity change $\delta \varrho$ producing an increase of $10 \%$ of the number of muons able to cross the volcano. For a daily number $N_{b}=100$ (i.e. $\Phi_{b}=10^{2}$ day $^{-1}$ ) of muons detected before the occurrence of the density change, we expect $N_{a}=110$ (i.e. $\Phi_{a}=1.1 \times 10^{2}$ day $^{-1}$ ) after the occurrence of the density change. Considering that the muon arrivals obey a Poisonian process, the standard deviation $\sigma_{N} \approx 10$ for both $N_{b}$ and $N_{a}$. Clearly, this makes $N_{b}$ and $N_{a}$ statistically indistinguishable. To be able to detect the density change, we have to consider longer periods of time to have better statistics. For instance, for a time period of 10 days, we expect $N_{b}=1000$, $N_{a}=1100$ with $\sigma_{N} \approx 32$, and $N_{b}$ and $N_{a}$ start to become distinguishable (at a rather poor significance level).

Mathematical developments given by Lesparre et al. [2010] and Jourde et al. [2016a] conduct to a feasibility formula where the statistical resolution, $\sigma_{\delta \varrho}$ of a given opacity change $\delta \varrho$ is expressed as a function of the total opacity $\varrho$ of the volcano, of the time resolution $\delta T$ that can be achieved, and of the detection characteristics of the telescope (Fig. 1.3). For a given telescope, the feasibility formula indicates that the smaller the opacity variations to detect, the poorer the time-resolution. Returning to the example of a $10 \%$ variation (i.e. $\epsilon=0.1$ in Fig. 1.3) of a flux $\Phi_{b}=10^{2}$ day $^{-1}$, Figure 1.3 shows that a duration $T_{\min }$ slightly less than 20 days is necessary to detect the change à flux at the $95 \%$ confidence level.

Another quantity considered in the feasibility formula is the telescope acceptance since the number of detected muons is proportional to $\mathcal{T}$. A way to improve the time-statistical resolution is to augment the acceptance by increasing the detection surface and/or the solid angle of capture of muons. An increase of the detection surface may be obtained either by augmenting the size of the pixellized detection matrices or by merging patches of lines of sight. 
In the later case, this will reduce the number of effective pixels and decrease the spatial resolution. Widening the solid angle of detection will also lead to a decrease of the spatial resolution.

To give some practical insight to the reader about the performances of muography for volcano applications, one can say that for the particular case of La Soufrière of Guadeloupe, the spatial resolution is on the order of 10 to $50 \mathrm{~m}$ depending on the distance from the telescope and due to the fan-like geometry of the lines of sight. The time resolution corresponding to the observed opacity changes is on the order of 1 to 3 weeks. As we shall see below, hydrothermal phenomena with time constants as short as a fraction of day seem to occur in the lava dome of La Soufrière. Such rapid phenomena cannot be detected with muography alone, and other geophysical methods with short time-resolution with a possibly poor spatial resolution (e.g. gravity measurements) can be used in conjunction with muography to document this type of rapid phenomena.

\subsubsection{Perturbing effects}

A frequent situation encountered in muography applied to volcanoes is that telescopes operate in open-sky conditions. This favors the occurrence of several undesirable phenomena that somewhat complicate data acquisition and some processing steps.

Effects of open-sky flux. The telescopes are exposed to the open-sky flux of muons that is much larger than the flux of muons of interest and coming from the target volcano. A very large number of detector hits are due to muons coming from elsewhere than the volcano and these unwanted events must be efficiently filtered out while preserving the particle trajectories coming from the target to image. Filtering is performed through coincidence criterion applied to at least three pixellized detectors as shown in Figure 1.2, and an event is declared valid if three aligned pixels are simultaneously fired on three matrices. Once applied, this filtering must be unbiased from missing-event probabilities. A first type of missed events is caused by the imperfect efficiency of the scintillator strips forming the matrices. A second type of missed events comes from the dead time of the detection electronics which is not able to detect another event during a period of time of about $200 \mathrm{~ms}$ following the detection of a previous event. For both types of missed events, the bias correction results in an increase of the flux of muons of interest. The parameters of the correction formula are experimentally determined on the field through calibration sessions where the telescopes are oriented toward the zenith. These dedicated calibration sessions may be completed with continuous re-calibrations performed by using events coming from open-sky trajectories located above of beside the volcano. 


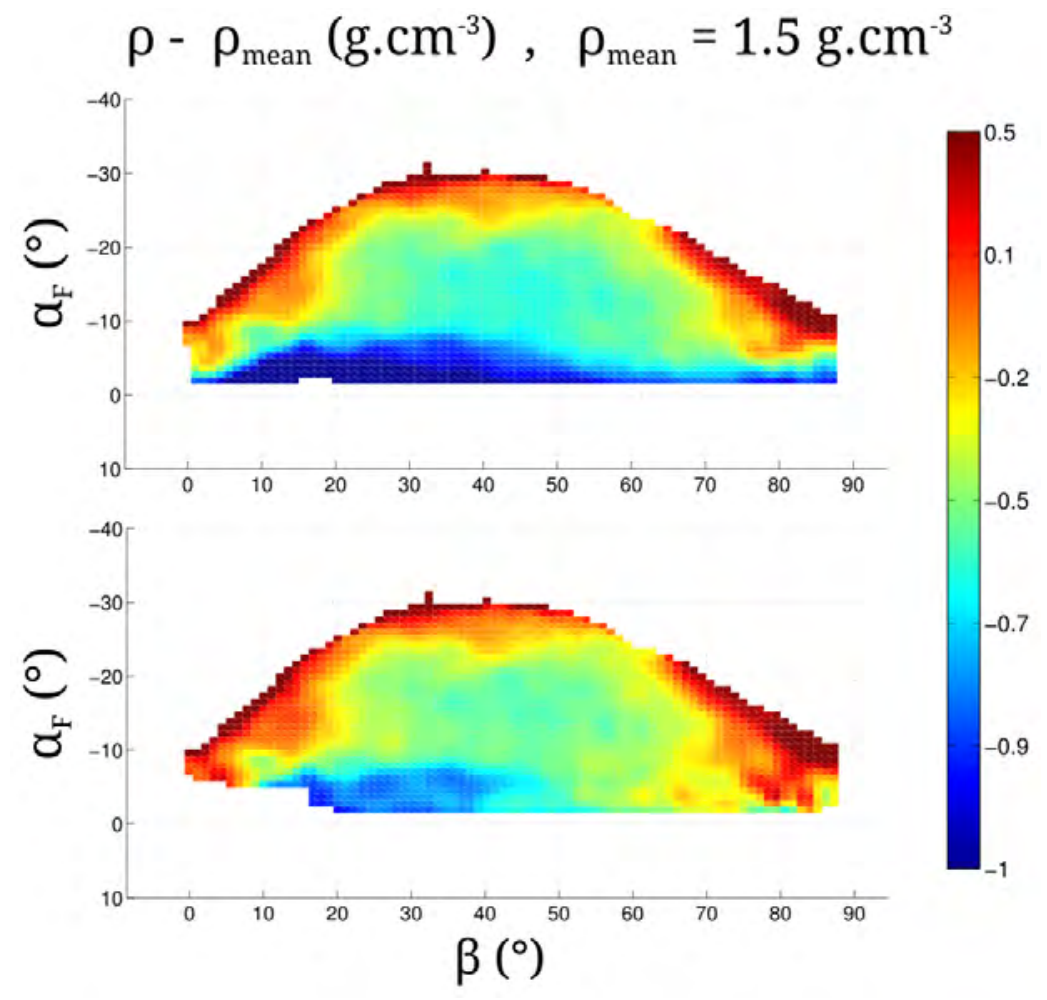

Figure 1.4: Example of upward flux correction in a muography of La Soufrière lava dome. Top: Uncorrected radiography with a spurious low-density layer at the bottom of the image (i.e. at near-horizontal inclinations). Bottom: Corrected image where the low-density layer has been suppressed. Reprinted from Jourde et al. [2013].

The open-sky flux of particles also counts high-energy electrons and positrons able to fire the detection matrices in a way similar to muons. These undesirable events may be eliminated by interposing a lead shield with a thickness of $5 \mathrm{~cm}$ in front of the center matrix of the telescopes.

Upward flux. This type of perturbing flux was discovered by us during experiments performed on Mount Etna and La Soufrière of Guadeloupe [Jourde et al., 2013]. This type of flux is composed of particles crossing the telescope in the reverse direction, i.e. hitting the rear matrix first, with trajectories identical to those of muons that crossed the volcano. In practice, particles forming the upward flux have trajectories with a small inclination below the horizontal and, consequently, only the trajectories with a small inclination above the horizontal when looking toward the volcano are biased (Fig. 1.4). These trajectories 
generally correspond to the largest thickness of rock and, consequently, to the smallest flux of muons crossing the volcano. The effects of the upward flux are then particularly strong with a significant alteration of the signal-to-noise ratio. If not corrected for, the upward flux produces an overestimation of the flux coming from the volcano and the resulting densities are biased toward low values. The correction of the upward flux needed an improvement of the clock systems of our telescopes in order to determine the sense of propagation of the particles through the measurement of their time-of-flight from one matrix to another [Marteau et al., 2014].

Scattered muons. Muon scattering is another perturbing effect to consider when doing muography of volcanoes and, more generally, in open-sky conditions. Scattering of low-energy muons represents a potentially important source of noise, particularly in transmission and absorption muography. The reconstructed trajectories of scattered muons have trajectories that mimic those of through-going particles. This results in an overestimate of the number of detected particles and to an underestimate of the target opacity [Nishiyama et al., 2016, Rosas-Carbajal et al., 2017, Gómez et al., 2017]. Contrarily to the other perturbing flux discussed above, scattered muons cannot be rejected by particle identification techniques,and data cleaning relies on models as given by Gómez et al. [2017]. To be reliable, these models must account for the topography of the geological structures and their surface density.

\subsection{Structural imaging of hydrothermal reservoirs in La Soufrière lava dome with joint muography, ERT and gravime- try}

Structural imaging of volcanoes is important for monitoring hydrothermal systems because it gives the general arrangement of the different subsystems that participate to the processes (e.g. reservoirs, fractures, barriers of massive lava). However, imaging of lava domes remains a difficult task for most geophysical methods because high-contrasts of material properties (e.g.several order of magnitude for electrical conductivity, large variations of seismic velocities) reinforce the non-linear nature of the associated inverse problems. Muographic imaging is much simpler because of the straight pathways of the muons across the rock. 


\subsubsection{Muography}

Survey characteristics. The role of structural imaging is to provide an as precise as possible $3 \mathrm{D}$ view of the volcano interior. In this respect, the more the data we have, the better the resulting model and, in the case of muography, this general principle translates into long acquisition times to have good signal-to-noise ratio and as many a possible angles of view to constrain the 3D tomography inversion. This later point is easily understood through the similarity of muography and CT X-ray imaging and the fact that high-resolution 3D tomography implies a fine angular coverage to constrain the inverse Radon transform. However, in the case of La Soufrière, only a small number of angular views are possible because of both the harsh field conditions and the expenditures inherent in the deployment of a large number of telescopes .

The first muography experiment performed on La Soufrière started in year 2008 with a single telescope. Since then, continuous measurements have been made with at least one telescope and, in the best situation, with up to five instruments located around the lava dome. Four of these telescopes are similar to the one shown in Fig. 1.2 with three detection matrices of $16 \times 16$ pixels of $5 \times 5 \mathrm{~cm}^{2}$. These telescopes are configured with high angular aperture to image the entirety of the lava dome. The fifth telescope is smaller with matrices of $10 \times 10$ pixels of $5 \times 5 \mathrm{~cm}^{2}$ and is located inside the 30 August Fault on the South-Eastern flank of the volcano. This instrument is configured to provide a close view of the most hydrothermally active region of the dome.

Data analysis. As explained in the preceding section, some processing steps are necessary to obtain density radiographies from muon counts measured by the telescopes.

The open-sky exposure of the telescopes makes some processing steps particularly critical. Such is the case of the filtering operations aimed at removing the perturbing scattered and upward fluxes described in previous sections. Other processing steps concern the filtering of fortuitous events, the bias correction of scintillator efficiency and the correction acceptance defects.

The resulting muographies as the one shown in Figure 1.4 display conspicuous opacity contrasts that reveal the strong density heterogeneities in the lava dome. In the particular case of La Soufrière, we recognize low-density domains corresponding either to presently active areas (principally the South Crater) or to ancient active areas. High-density domains indicate the presence of massive lava volumes. 


\subsubsection{Electrical resistivity tomography (ERT)}

The ERT experiments briefly presented below are discussed in details by Nicollin et al. [2006], Lesparre et al. [2014] and Rosas-Carbajal et al. [2017].

Complementarity of ERT compared to muography. ERT brings information about rock electrical conductivity, possibly complex-valued in the case of electrical impedance tomography (EIT) measurements [Zimmermann et al., 2008]. ERT measurements are highly sensitive to the presence of fluids as, in general, their electrical conductivity is much higher than that of the rock matrix. Even a small amount of liquid can increase the bulk rock conductivity by several orders of magnitude [Archie, 1942], and ERT is an efficient method for constraining the volume of fluid-saturated rocks in a volcano.

Contrarily to muography, ERT tomography cannot be performed from a remote location and numerous electrodes must be placed on and around the volcano to perform a 3D inversion such as the example shown in Fig. 1.5 [Rosas-Carbajal et al., 2017]. Although ERT is a potential-field method with an infinite-distance sensitivity, one may reasonably assume that the electrical current that flows from positive to negative injection electrodes (there may be several electrodes of each type) is contained within a finite-size volume. However, contrarily to muography, the precise geometry of this volume is unknown because it depends on the conductivity distribution which is precisely what we look for. This makes ERT a highly non-linear inverse problem with a moderate to low spatial resolution when compared to muography. Provided an array of electrodes remains in place, ERT may be used to perform a monitoring with a time resolution as fine as some minutes [e.g. Binley et al., 2015]. A joint analysis of ERT and muography data may be very helpful to resolve ambiguities in interpretations. For instance, muography may be used to decide whether an anomaly with a large electrical resistivity corresponds to a void or to a block of massive andesite.

Survey characteristics and data analysis. The ERT data were collected through experiments with electrode transects extending through La Soufrière lava dome and around it [Rosas-Carbajal et al., 2017, Fig. 1]. Three-dimensional protocols with non-aligned electrodes where used to better resolve the innermost regions of the lava dome [Lesparre et al., 2014]. Because of the harsh field conditions, the ERT series of experiments was conducted from 2003 to 2011 to collect about 23000 data points. The 3D inversion of the data was performed with a least-squares algorithm with smoothness-constrained regularization of the inversion for a model counting about $10^{6}$ mesh cells [Johnson et al., 2010].

Several conductive regions $\left(\geq 0.1 \mathrm{~S} . \mathrm{m}^{-1}\right)$ are found in the lava dome, the largest located in the volcano's southern flank (Fig. 1.5). The southern conductive body contains a sub-domain of $10^{7} \mathrm{~m}^{3}$ with a conductivity larger than 
$1 \mathrm{~S} . \mathrm{m}^{-1}$. Such high conductivities are likely to correspond to active pathways of acid hydrothermal fluids emanating from deepest regions of the hydrothermal system and rising toward the presently active parts on top of the lava dome. Other conductive bodies located on the eastern and north-western sides of the lava dome appear disjoint from the southern conductive reservoir and are likely to correspond to fossil hydrothermal reservoirs with no visible present activity.

\subsubsection{Gravity survey}

A gravity survey performed on La Soufrière is presented by Rosas-Carbajal et al. [2017]. Mathematical developments concerning the joint inversion of muography and gravity data are given by Jourde et al. [2015] (see also [Nishiyama et al., 2014, Barnoud et al., 2019, Cosburn et al., 2019]).

Complementarity of gravimetry compared to muography. Both gravity measurements and muography bring direct information about the rock density and, for this reason, joint inversion of both type of data appears natural. As explained in detail by [Jourde et al., 2015], the sampling kernels of both methods strongly differ: gravity measurement are sensitive to the whole Earth's density distribution with a $r^{-2}$ weighting while muography data only depend on the density distribution located inside bounded elongated and conical volumes whose axis correspond to the lines of sight of the telescope. This difference makes the gravity method a low-resolution in space while muography is potentially a high-resolution method, depending on the telescope arrangement used.

Despite the fact that muography actually samples a finite volume (i.e. the union of the conical lines of sight) of the density distribution, it can be shown that the information brought by muography improves the spatial resolution outside this volume when a joint inversion with gravity data is performed [Jourde et al., 2015]. Gravity data may also bring information useful to constrain the density distribution in gaps between lines of sight. Another interest of gravity data is their usefulness to bring information to reduce the bias in the density values determined by muography and caused by low-energy muon scattering.

Survey characteristics and data analysis. The data set counts 103 gravity measurements done between March 2014 and February 2015 with a Scintrex CG-5 gravimeter [Rosas-Carbajal et al., 2017]. The precision is about $10 \mu \mathrm{Gal}$. Methodological details for data processing prior to inversion, including drift, tides, and ellipsoid and topography corrections are given by Jourde et al. [2015]. The correlation between the topography and the Bouguer anomaly [Jourde et al., 2015, Nettleton, 1939] is minimum for an optimal Earth den- 

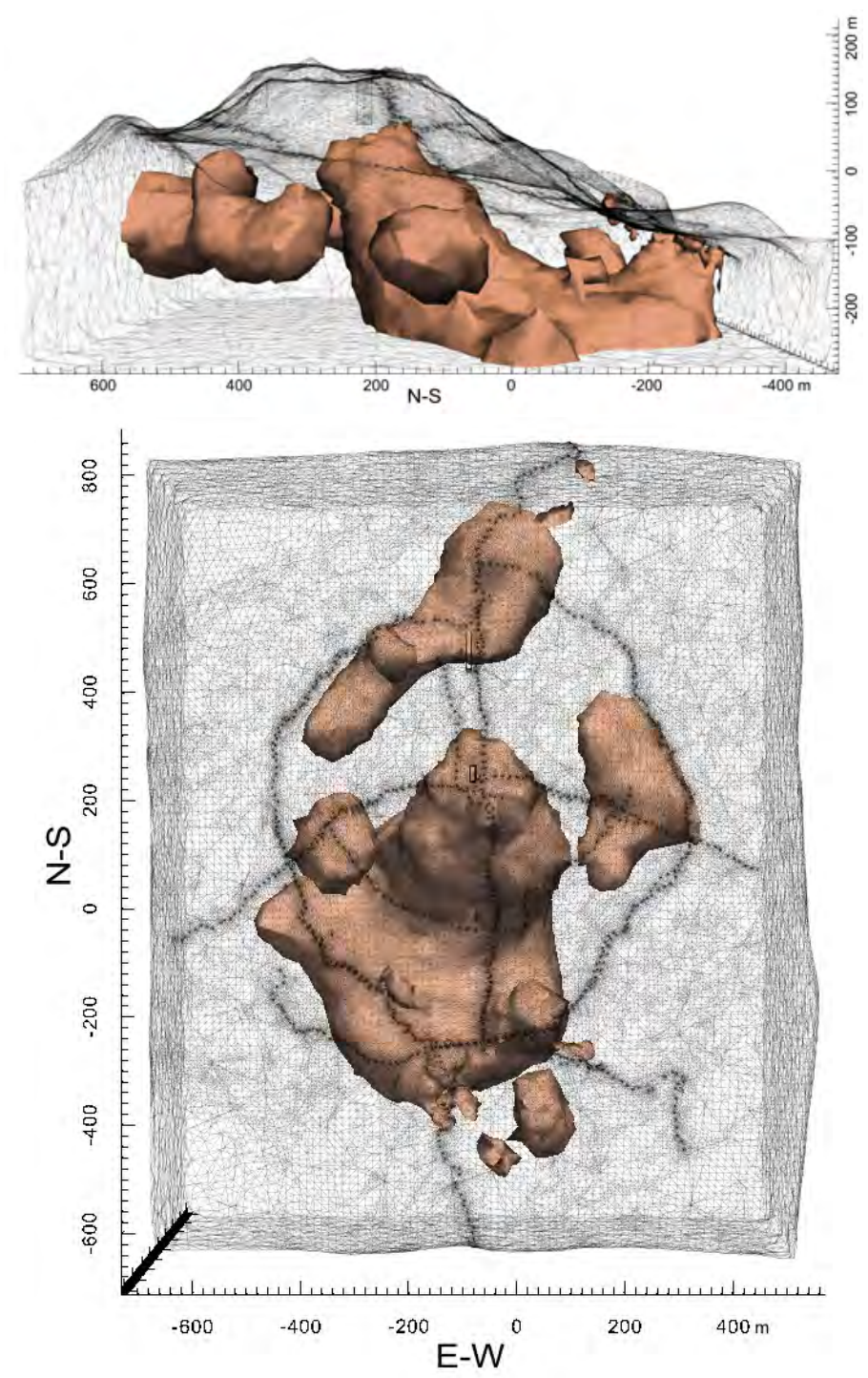

Figure 1.5: Main electrically conductive structures found with 3D ERT of La Soufrière lava dome (brown volumes) [Rosas-Carbajal et al., 2016]. (top) N-S section view, (bottom) plan view. The meshing of the numerical forward model is shown by the thin black lines. In the plan view, the black dots correspond to the electrode positions. 
sity of 1.75 g.cm ${ }^{-3}$ [Parasnis, 1952]. This low value indicates that the lava dome is highly heterogeneous and contains a significant fraction of voids and of unconsolidated hydrothermaly altered materials. The heterogeneity of the lava dome is confirmed by a 3D model of the density distribution obtained by jointly inverting gravimetry and muography data (Fig. 1.6).

\subsection{Functional imaging of sudden hy- drothermal events with joint muog- raphy, seismic noise and fumarole temperature}

Functional imaging involves continuous measurements from an ensemble of techniques providing complementary data to constrain the phenomena of interest. In the present case, hydrothermal processes occurring in the lava dome are likely to produce temperature variations at fumarole vents, density variations due to phase changes in hydrothermal reservoirs, and seismic noise caused by multiphase flows and oscillations of fluids in conduits.

In the next sections, we present a field-experiment with an emphasis on the detection of sudden events with time constants of hours and days. To detect such events, we implemented a high time-resolution array of temperature $(1 \mathrm{~s}$ sampling interval) and seismic sensors (4 ms sampling interval) located on the summit of the lava dome together with one telescope located inside the 30-August fracture (Fig. 1.1). We focus on a particular event that occurred during a 3-day period of year 2017, from 28 March 12:00 UTC to 31 March 12:00 UTC. During this period, the weather conditions were very calm and produced seismic data with a very high signal-to-noise ratio.

\subsubsection{Temperature at fumaroles}

Experimental setup. The temperature at the vents of the South crater was measured every second by Pt1000 probes inserted several tens of centimeters in the conduit of the vents. The Pt1000 were connected with a 4 -wires protocol to a Gantner A107 Analogue-to-Digital 19 bit module and the numerical data were transferred to a Gantner QStation data concentrator through a RS485 serial data bus. All data were time-stamped through a GPS clock. The temperature time-series of the Northern vent of the South Crater is shown in Fig. 1.7A. This vent is the northern most of the three fumaroles of the South Crater (labelled CS in Fig. 1.1). 

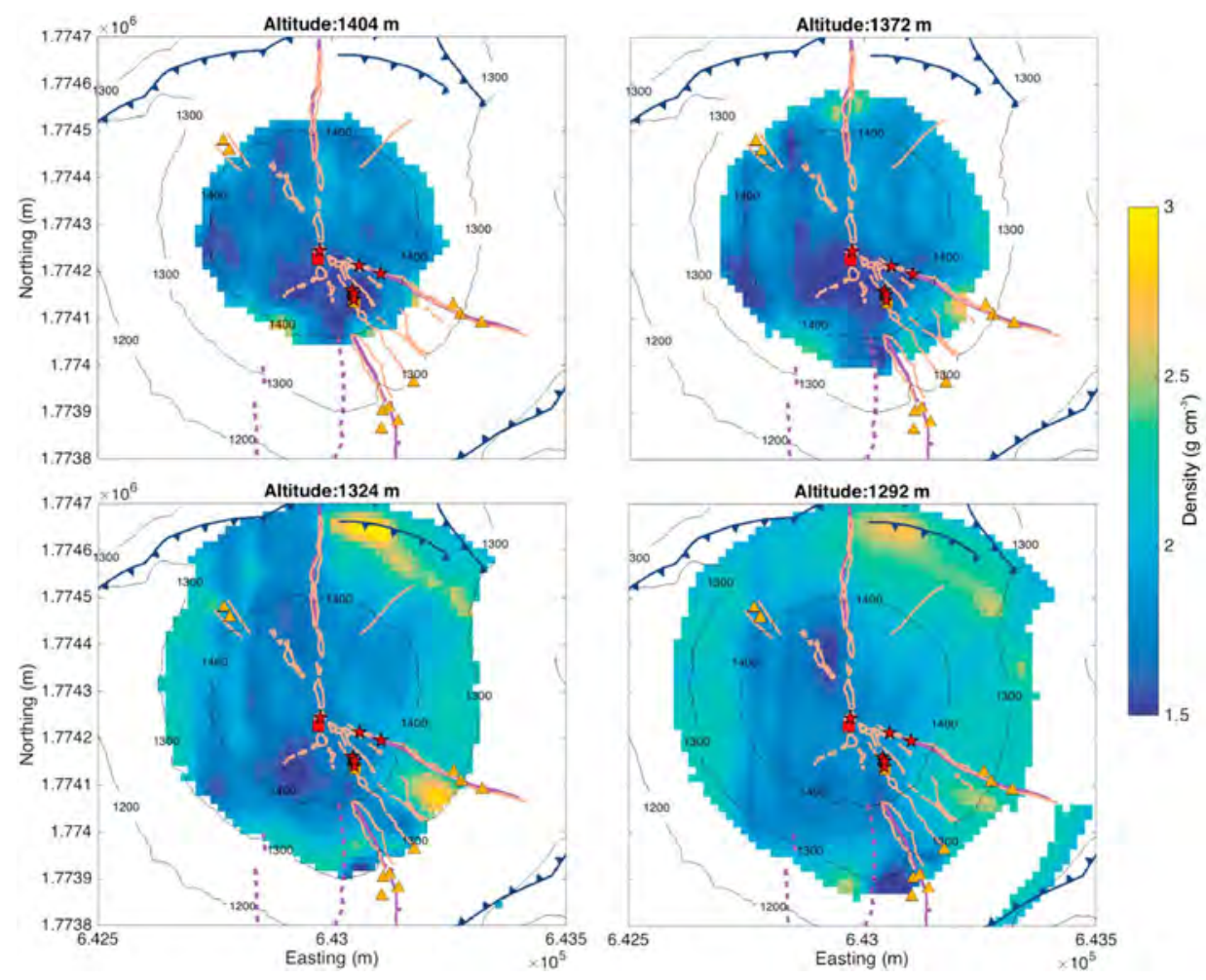

Figure 1.6: Horizontal slices of a 3-D density model at various altitudes within the dome of La Soufrière obtained from the joint inversion of muography and gravity data. Orange lines: fractures; violet lines: faults with triangles indicating fault direction; blue lines: collapse scars; orange symbols: past activity; red symbols: present activity; triangles: hydrothermal fluid springs; stars: active fumaroles; squares: boiling acid ponds. Reprinted from Rosas-Carbajal et al. [2017]. 


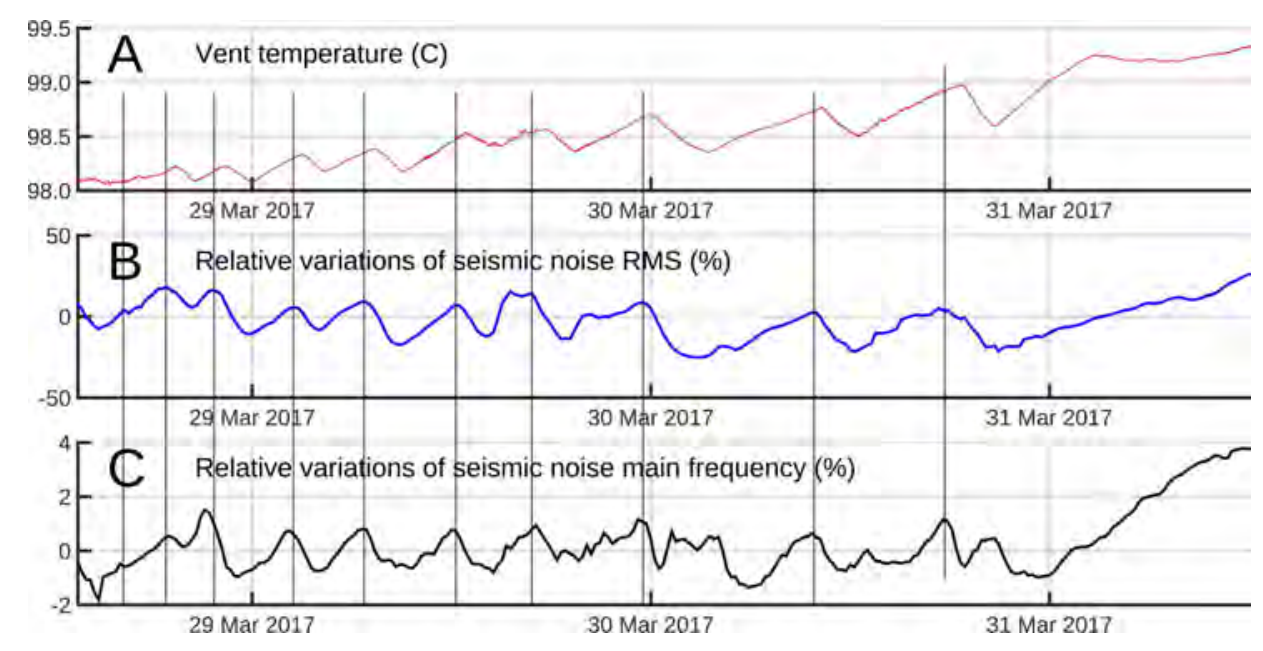

Figure 1.7: Time variations of vent temperature (in degrees Celsius) and seismic noise RMS and dominant frequency. a) Temperature in the North vent of the South crater. b) Relative variations (in percent) of the seismic noise energy in the 3-6 $\mathrm{Hz}$ frequency band. c) Relative variation (in percent) of the dominant frequency in the $3-6 \mathrm{~Hz}$ spectral band. The thin black vertical lines mark the relative maxima of seismic RMS that fall nearby temperature maxima. Observe the delay of about 45 $\mathrm{mn}$ of the temperature maxima with respect to those of the seismic noise RMS. The sampling interval of temperature data is 1s and the seismic attributes (RMS and dominant frequency) are computed for time windows of 20s. Reprinted from

Le Gonidec et al. [2019]. 
${ }_{472}$ 1.5.2. Seismic noise measurements of about $1.2 \mathrm{C}$. by checking if the start dates, $t_{n}$, of the cycles obey:

$$
t_{n}-t_{c}=\tau \times \lambda^{n},
$$
scaling ratio such that,

$$
\lambda=\frac{t_{n+2}-t_{n+1}}{t_{n+1}-t_{n}} .
$$
transformation, [Shanks, 1955, Bender and Orszag, 2013],

$$
t_{c}=\frac{t_{n-1} \times t_{n+1}-t_{n}^{2}}{t_{n-1}+t_{n+1}-2 t_{n}}
$$
the appearance of the visible oscillations.

Data analysis. Defining a cycle as the time period separating two successive local minima in the temperature record, 10 such cycles may be identified in the curve of Fig. 1.7A. Fig. 1.8 shows that the duration of the successive cycles increased from 3 hours (cycle 1) to 8 hours (cycle 9). Splitting a cycle into a fall and a rise period, one observes that the fall period remains almost constant near 2 hours for all cycles (Fig. 1.8B). Conversely, the rise period increases from 2 hours to 6 hours when progressing along the series of cycles (Fig. 1.8C). The increase of the duration of the rise period explains the positive trend visible in the total cycle duration (Fig. 1.8A). Another positive trend is superimposed on the cycle sequence with an average temperature rise of $0.1^{\circ} \mathrm{C}$ between successive temperature minima (Fig. 1.8D). The temperature decrease occur during the fall period steadily trends from $0.15{ }^{\circ} \mathrm{C}$ to $0.4{ }^{\circ} \mathrm{C}$ along the cycle sequence (Fig. 1.8E), and the temperature increment in the successive rise periods increases from $0.15{ }^{\circ} \mathrm{C}$ to $0.65{ }^{\circ} \mathrm{C}$ (Fig. 1.8F). The global positive trend superimposed on the oscillation pattern produces a net increase of temperature

The oscillating pattern observed in the temperature time series resembles to reverse log-periodic sequences as observed financial time series [Sornette and Zhou, 2002]. The log-periodicity of the temperature cycles can be tested

where $t_{c}$ is the data marking the onset of the critical transition, $n$ is the cycle index increasing with time, $\tau$ is the time unit (e.g. hour or day), and $\lambda$ is the

For the temperature data of Fig. 1.7, we obtain $\lambda=1.3$. Using a Shanks

we obtain $t_{c} \approx-15 \mathrm{~h}$, indicating that the sequence of temperature cycles critically converges backward in time to a date approximately half a day before

Experimental setup.. The ambient seismic noise is sampled at a frequency of $250 \mathrm{~Hz}$ with an array of Geo Space GS-11D vertical geophones with a low-pass 

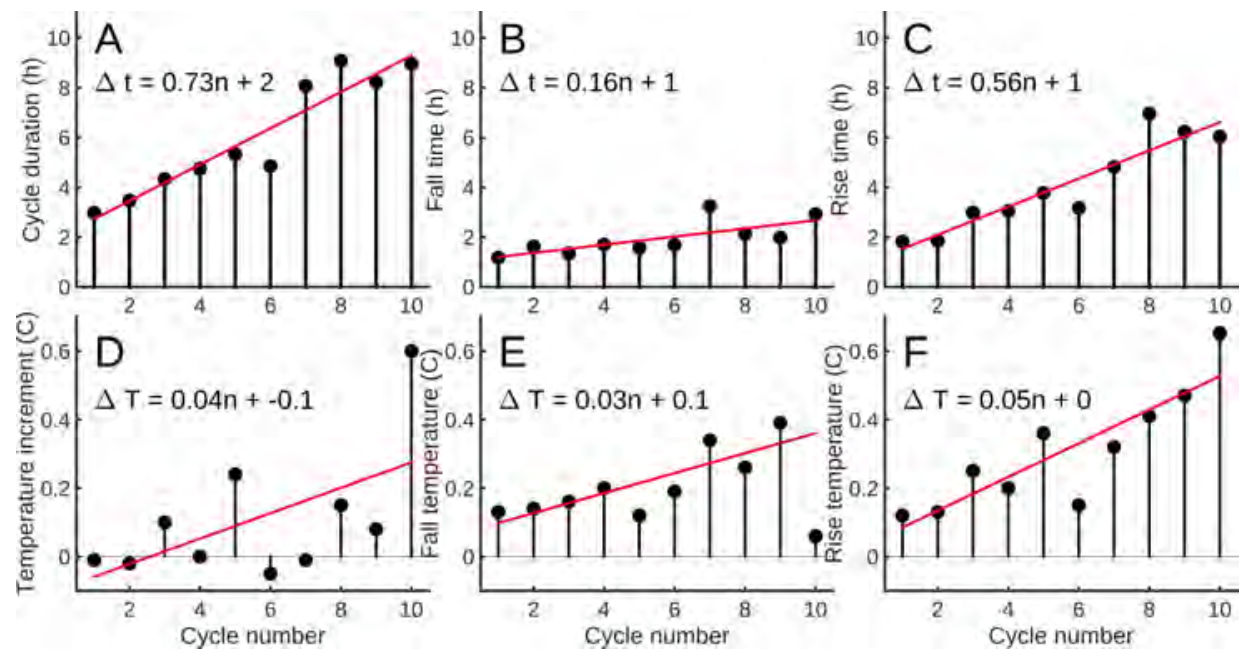

Figure 1.8: Characteristics of the temperature cycles identified (separated by thin vertical lines) in Figure 1.7 represented as a function of cycle number. A) Cycle duration; B) fall-time; C) Rise time; D) Temperature increment; E) Fall temperature; F) Rise temperature. Reprinted from Le Gonidec et al. [2019].

cut-off frequency of $3 \mathrm{~Hz}$. Gantner A108 Analogue-to-Digital 19 bit modules are used to convert the analog signals to numerical data transferred to a Gantner QStation data concentrator. A common GPS time base is used for both temperature and seismic data. Two groups of 8 geophones form heptagonal arrays located East of the Tarissan crater and North of the Napoléon crater (NN array) and midway between Tarissan and South craters (POCS array (Fig.1.1). Three geophones are aligned along the fracture of the South crater (SC). Because of their location on top of the lava dome, the geophones are very sensitive to noise induced by meteorological conditions and anthropogenic noise (e.g. tourists walking on the summit).

Data processing.. The SC and NN data were discarded because of a too low signal-to-noise ratio, and only the POCS data have been used to compute the RMS and the dominant frequency time-series of Fig. 1.7B,C. Both the RMS and the dominant frequency were computed for data segments of $20 \mathrm{~s}$ and for the $3-6 \mathrm{~Hz}$ range where the spectral coherency is maximum [Le Gonidec et al., 2019]. Both the seismic RMS and dominant frequency time series display the same oscillating pattern as observed in the temperature time series of Fig. 1.7A. The oscillations of the seismic RMS are advanced by $43 \pm 11$ min with respect to the temperature oscillations. Similarly, the dominant frequency curve is advanced by $48 \pm 14 \mathrm{~min}$. These delays eliminate the possibility that the vents 
themselves are the source of the seismic noise.

The source of seismic noise is localized by back-propagating the delayed seismic traces recorded by the geophones (POCS array geophones, $2 \mathrm{NN}$ geophones and 2 SC geophones). Time lags are determined by searching the maximum value of the cross-correlation between all pairs of seismic time-series. The time lags are averaged for the 3-day period of data. Prior to cross-correlating, the raw data are band-pass filtered in the $3 \mathrm{~Hz} \leq f \leq 25 \mathrm{~Hz}$ frequency band where significant spectral coherency is observed for most pairs of seismic timeseries. Because of the lack of published seismic-velocity model for the lava dome, we use a constant velocity to back-propagate the delayed wavefronts. In the present study, the best refocusing of the wave-fronts is obtained for a seismic wave velocity around $500 \mathrm{~m} / \mathrm{s}$ in good agreement with the recent model of volcano seismic velocities proposed by Lesage et al. [2018]. The source volume is defined as the ensemble of voxels where at least 8 wavefronts refocus simultaneously. The source volume is represented in yellow in Fig. 1.9 and is rather small, i.e. $10^{4} \mathrm{~m}^{3}$, but apparently connected to one of the major fracture and fumarole systems of the volcano.

\subsubsection{Muography experiment}

Experimental setup. The telescope used in the present study was equipped with three parallel detection matrices of $10 \times 10$ pixels of $5 \times 5 \mathrm{~cm}^{2}$. The two extreme matrices were $1 \mathrm{~m}$ apart. All matrices were synchronized by the same master clock signal with a timing resolution better than 1 ns. No lead shield was used since the telescope lay deep in a fault where surrounding rocks naturally filter low-energy scattered particles that constitute the dominant source of noise [Gómez et al., 2017]. For this telescope, the view field counted $M=$ $19 \times 19=361$ lines of sight, and the solid angle spanned by each line $\mathcal{L}_{k}$ could be adjusted by tuning the distance between the front and the rear matrices. The telescope setup was: azimuth $=345^{\circ}$; inclination $=28.5^{\circ} ; X_{U T M}=20 \mathrm{~N} 643115$; $Y_{U T M}=1773938$; above m.s.l. In order to increase the acceptance and improve the space- and time-resolution we merged lines of sight (see Extended Data Fig. 1 in Le Gonidec et al. [2019]).

Monitoring with cosmic muons. The source of the seismic noise associated to the oscillation sequence (Fig. 1.7) was located inside the observation cone of the muon telescope (Fig. 1.1). The time-resolution is about 10-20 days and the variance of the muons counts was reduced by merging adjacent lines of sight to increase the acceptance [Jourde et al., 2016a]. The muons count timeseries (Fig. 1.10) extends from 8 January to 14 April 2017 to largely encompass the 3-day period where we evidenced the correlated events in the temperature and seismic data. Fig. 1.10 displays the muon count time series in 4 areas: 


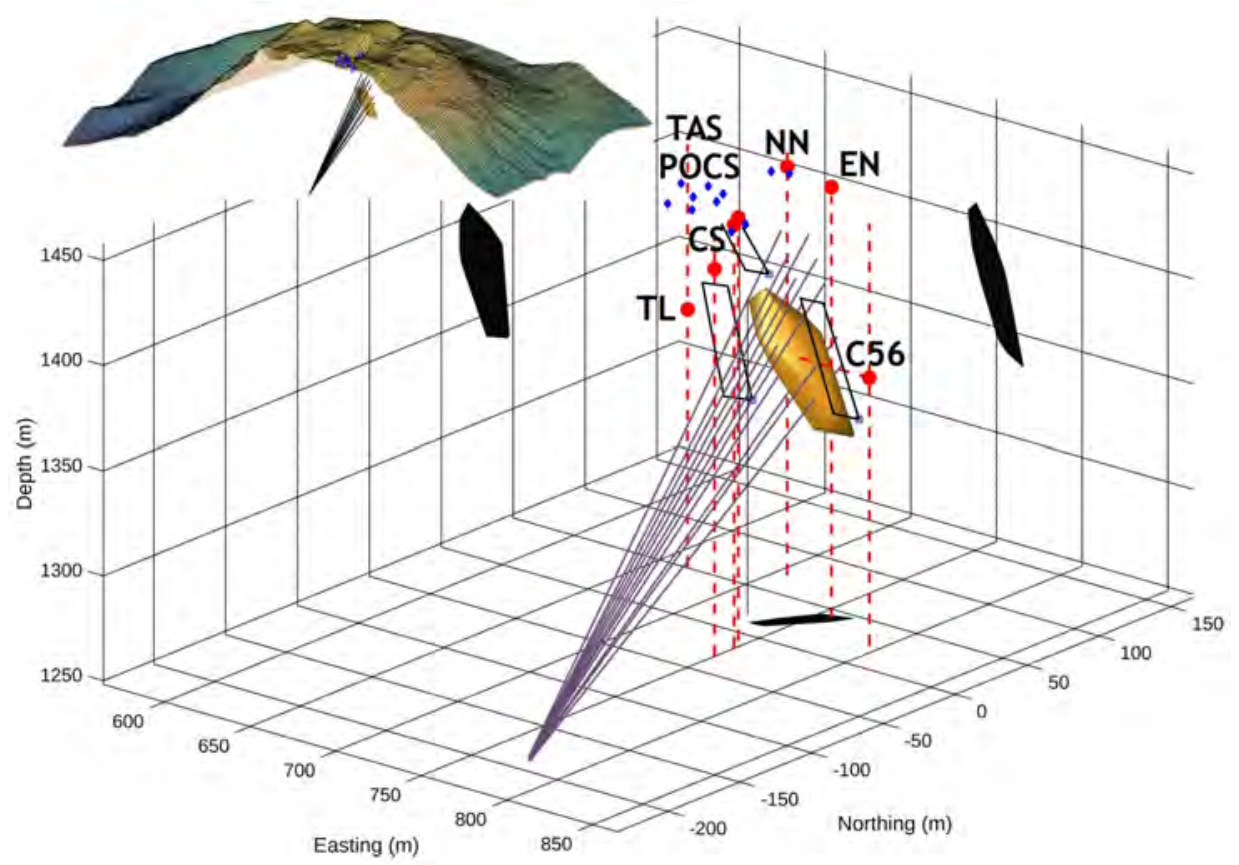

Figure 1.9: Location of the seismic noise source volume. The yellow body represents the $3 \mathrm{D}$ convergence zone of the seismic wavefronts recorded by the geophones of the POCS, CS and NN areas on top of the lava dome (blue dots). This volume is reconstructed by back-propagating the time lags of seismic signals and is likely to contain the sources of the seismic noise. The red dots represent the main active vents. The black patches are the projections of the source volume onto the faces of the 3D block diagram. The fan-like bundle of straight lines represents the lines of sight of the muon telescope crossing the active hydrothermal region and used to obtain the red curve in Fig. 1.10. The 3 black rectangles located above and on each sides of the source zone show the 3 adjacent areas corresponding to the curves labeled 2, 3 and 4 in Fig. 1.10. The telescope is located at the apex of the fan-like pattern. The inset shows the position of the seismic source zone in the lava dome (see Extended Data Fig. 6 for an enlarged version). The red dots mark the main fumaroles TAS $=$ Tarissan crater, TL Tarissan acid pond, C56 $=56$-crater fumaroles, $\mathrm{CS}=$ South crater fumaroles, $\mathrm{NN}=$ North Napoléon fumarole, $\mathrm{EN}=$ East Napoléon fumarole. POCS = main array of geophones used in the present study. The vertical dashed red lines passing through the fumaroles markers are upward-continued to the top of the lava dome to better show that TL and G56 are located in pits about $80 \mathrm{~m}$ below the surface. Reprinted from Le Gonidec et al. [2019]. 
one centered on the source of the seismic noise (red curve of Fig. 1.10), and three areas located to the left, the right and above (blue curves in Fig. 1.10). On 4 April 2017, we see a sharp increase in the muon count occurring in the region of the seismic source while the other three areas remain stationary. The time-resolution of the curves displayed in Fig. 1.10 is not as fine as in Fig. 1.7. However, we remark that a possible moderate increase may occur as soon as 31 March when the descending phase of the flux oscillation is interrupted. Consequently, there is possibly a delay of up to two days between the beginning of the temperature and seismic oscillations shown in Fig. 1.7 and the onset on increase of muon flux.

\subsubsection{Dynamics of the shallow hydrothermal system}

The remarkable correlation observed in the oscillating time series of both temperature and seismic noise attributes (Fig. 1.7) suggests a causal link between the temperature measured in the vents and the activity of the source of seismic noise localized using both the seismic and the muons data (Fig. 1.9 and 1.5). This source volume appears vertically elongated over more than $50 \mathrm{~m}$ and slightly inclined southward. Such a shape is partly a consequence of the geometry of the geophone array which is located only on the western side of the source. Its lower part is connected to the 56-fracture which extends West-East from the Napoléon to the Breislack craters (Fig. 1.1 and 1.11a). The sharp decrease in opacity observed in the source volume located within the lava dome may be explained by the rapid invasion of steam flushing a liquid phase (Fig. $1.11 b)$. This is likely due to the convective destabilization of hydrothermal fluids triggering an ascent of hot fluids with increased gas fraction in the deep part of the 56-fracture network. These hot fluids are likely to reside in the lava dome and in the first hundreds of meters below. In this scenario, the oscillations shown on Fig. 1.7 are early-warning phenomena that occur at the very beginning of the process with the first signs of destabilization within the source volume (Fig. 1.11a). We check this idea by analyzing the temperature oscillations as a log-periodic sequence [Sornette, 2006] to estimate the occurrence time of an eventual singular event marking the destabilization. We find this occurrence about 15 hours before the appearance of the first visible oscillation.

The time-variations in the dominant frequency of the seismic noise (Fig. $1.7 \mathrm{C}$ ) may reflect long-period changes of the physical conditions in a resonator formed by a fracture network filled with a liquid-bubble mixture of high bulk compressibility, high density and low sound velocity (Fig. 1.11). The small variations of the dominant frequency may be reproduced by varying the sound velocity in a Helmholtz-like resonator system. Using the data modeling results 

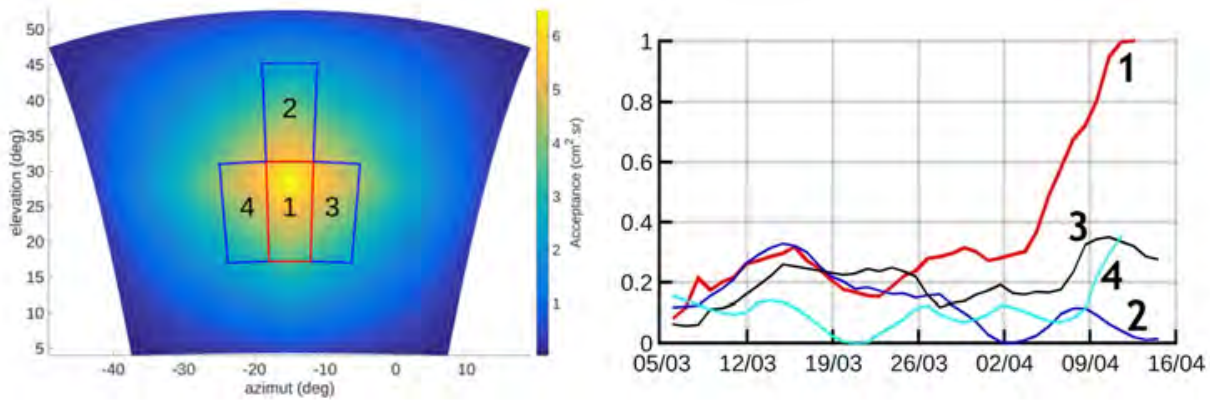

Figure 1.10: Time variations of the muon flux across different domains of the dome of La Soufrière. The red curve is for the bundle of lines of sight covering the seismic source zone of Fig. 1.9. The other three curves are for adjacent areas labeled 2, 3 and 4 in the inset showing the acceptance function of the telescope's view-field.

Oscillation amplitudes are arbitrarily set to a common value. The total acceptance of bundles of lines of sight crossing the source area 1 is $54.3 \mathrm{~cm}^{2}$.sr. The acceptances of the merged lines of sight in the areas 2,3 and 4 are respectively $34.8 \mathrm{~cm}^{2} . \mathrm{sr}$, $40.3 \mathrm{~cm}^{2}$.sr, and $45.8 \mathrm{~cm}^{2}$.sr. For comparison, the maximum acceptance of the axial line of sight of the telescope equals $6.5 \mathrm{~cm}^{2}$.sr. Adapted from Le Gonidec et al. [2019]. 
shown if the Fig. 9b of the article published by Kieffer [1989], we derive the mass fraction $\varphi$ of steam necessary to reproduce the observed frequency variations. We find that a minimum mass fraction $\varphi=11 \%$ is necessary to obtain a physical solution and that variations of $0.25 \%$ above this value are sufficient to reproduce the data. The frequency jump visible after 31 March (Fig. 1.7C) requires a $\varphi$ increase of $0.75 \%$. Such a mass fraction corresponds to a volume fraction of steam around $97 \%$ at pressures less than 10 bars. This would imply a steam flow in either a slug or annular flow regime [Abdulmouti, 2014]. These types of flow are known for their violent dynamics [Lane et al., 2001]. and thus for their efficient seismic emissivity [Hellweg, 2000]. Two-phase flows in conduit networks are reported to be intrinsically unstable and prone to oscillations sustained by turbulent movements and density waves [Fujita et al., 2011, Dartevelle and Valentine, 2007]. In many instances, the period of the density waves is proportional to the wave time-of-flight required to cross the system [Kakac and Bon, 2008]. Within this phenomenological context, the observed increase of the oscillation period in the temperature and seismic times series (Fig. 1.7) may reflect a progressive extension of the size of the fracture network occupied by the two-phase flow (Fig. 1.11A). This extension may result from an enhanced extraction of the gaseous phase caused by the pressure oscillations [Luo et al., 1999] that may produce local negative pressure anomalies in the deep parts of the draining network. This kind of positive feedback could eventually lead to an abrupt jump of steam production exceeding the transport capacity of the surface vents and leading to explosive events. Owing to these observations, we consider that the 56-fracture of La Soufrière lava dome is prone to destabilization and represents an area of potentially high risk level. The fact that this fracture was the first to activate at the very onset of the two last phreatic eruptions in 1956 and 1976 ([Rosas-Carbajal et al., 2016, Moretti et al., 2020] and references therein); further confirms this argument The temperature trend observed along the cycle of temperature oscillations may be due to a constant steam supply causing a progressive increase of the pressure in the source zone of Fig. 1.9. As revealed by gas geothermobarometry from fumarolic fluid chemistry, this increase peaked in the April-May 2018 excursion through the water critical point of water of the boiling hydrothermal portion feeding summit fumaroles [Moretti et al., 2020]. Our integrated methodology could then represent a monitoring technique able to track the hydrothermal evolution well before that changes of $\mathrm{P}, \mathrm{T}$ and composition are recorded by fumarolic fluids. 


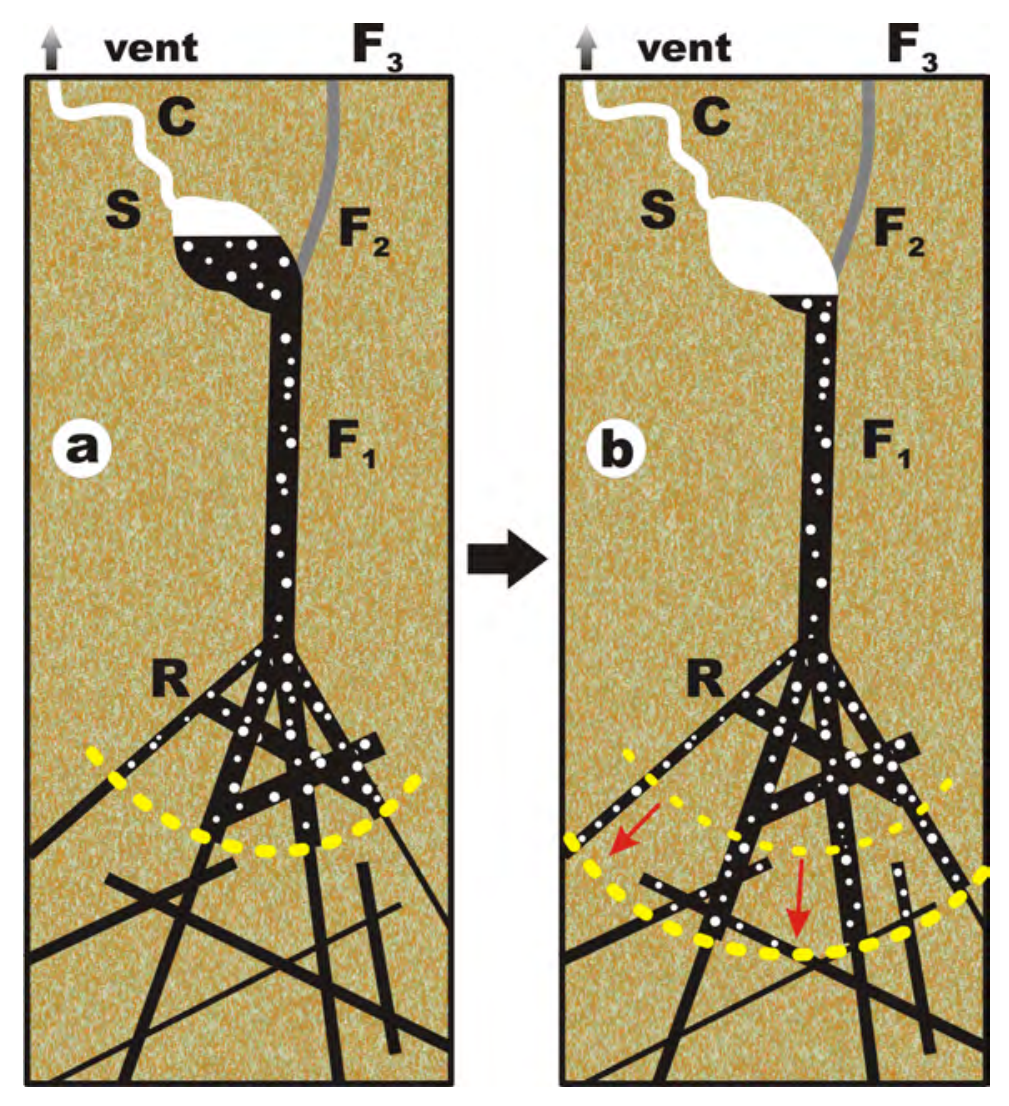

Figure 1.11: Conceptual view of the destabilization process as documented by the temperature, seismic and muon data. a) The lower part of the 56-fracture (F1) is filled with a mixture of liquid and rising bubbles coming from a lower feeding reservoir R. The two-phase flow is subject to density-waves oscillations causing hammering in the upper part $\mathrm{S}$ of the system corresponding to the yellow elongated volume of Fig. 1.9. S emits seismic noise and transmits pressure oscillations in the vent through the tortuous conduit $\mathrm{C}$. As the volume of $\mathrm{R}$ increases (symbolized by red arrows and expanding yellow dashed lines), the period of the density waves increases as observed in Fig. 1.7. b) The increase of steam production causes an overpressure that flushes the liquid from S. This produces a huge decrease of density as seen in the muon telescope data of Fig. 1.10. F2 = low-permeability segment of the 56-fracture preventing strong surface emissions in the upper open segment F3 and favoring a deviation of the flux toward the South Crater vents through S and C. Adapted from Le Gonidec et al. [2019]. 


\section{1.6. Conclusion}

${ }_{642}$ Bibliography obtained. 14-CE-04-0001. 240, 2014.

During the past decade, muography has progressively acquired a state of the art that makes this technique operational in many domains of Earth Sciences like, for instance, civil engineering, hydrology, archaeology and volcanology. This latter domain was among the firsts to be explored and it is now considered that muography belongs to the toolbox of imaging techniques available to study processes at work in active volcanoes. In the present chapter, with help of the case study of La Soufrière volcano, we show how muography can be used to obtain information both for structural imaging and functional imaging problems. We also show all the benefits that can be obtain by joining muography with other geophysical techniques like electrical resistance tomography, passive seismic monitoring, gravimetry and temperature measurements.

In the particular case of transient signals caused by rapid fluid movements and phases changes occurring in the shallow hydrothermal system described above, the time-resolution of muography is not sufficient to unambiguously detect the emergence of the phenomena at work. However, by joining muography data with high time-resolution data like temperature measurement in vents and passive seismic data, both a good space and time resolution can be

Further improvements could be obtained by using larger muon telescopes with high acceptance to improve the time resolution [Lesparre et al., 2010, Jourde et al., 2016a]. Coupling several telescopes placed at different stations around the volcano will also improve the 3D location of active hydrothermal focus. Other types of measurements like multi-gas and high time-resolution deformation, could also help to better constrain models and improve our understanding of rapid phenomena that might produce dangerous events.

Acknowledgement. We warmly thank our colleagues from the OVSG, and Fabrice Dufour (deceased on 29 July 2016), Christel Dufour, and Aurélie Tallard-Breton for their help during the many field operations we performed since year 2008. The studies presented in this chapter were funded through ANR projects: DOMOSCAN ANR-08-RISKNAT-002-01 and DIAPHANE ANR-

H. Abdulmouti. Bubbly two-phase flow: Part I-characteristics, structures, behaviors and flow patterns. American Journal of Fluid Dynamics, 4(4):194-

G.E. Archie. The electrical resistivity log as an aid in determining some reser- 
voir characteristics. Transaction of the American Institute of Mining and Metallurgical engineers, 146:54-61, 1942.

A. Barnoud, V. Cayol, V. Niess, C. Carloganu, P. Lelièvre, P. Labazuy, and E. Le Ménédeu. Bayesian joint muographic and gravimetric inversion applied to volcanoes. Geophysical Journal International, 218(3):2179-2194, 2019.

C.M. Bender and S.A. Orszag. Advanced mathematical methods for scientists and engineers I: Asymptotic methods and perturbation theory. Springer Science \& Business Media, 2013.

A. Binley, S. Hubbard, J. Huisman, A. Revil, D. A Robinson, K. Singha, and L.D. Slater. The emergence of hydrogeophysics for improved understanding of subsurface processes over multiple scales. Water Resources Research, 2015.

G. Boudon, A. Le Friant, J.-C. Komorowski, C. Deplus, and M. Semet. Volcano flank instability in the lesser antilles arc: diversity of scale, processes, and temporal recurrence. Journal of Geophysical Research: Solid Earth, 112(B8), 2007.

G. Boudon, J.-C. Komorowski, B. Villemant, and M. Semet. A new scenario for the last magmatic eruption of la soufrière of guadeloupe (lesser antilles) in 1530 ad evidence from stratigraphy radiocarbon dating and magmatic evolution of erupted products. Journal of Volcanology and Geothermal Research, 178(3):474-490, 2008.

D. Carbone, D. Gibert, J. Marteau, M. Diament, L. Zuccarello, and E. Galichet. An experiment of muon radiography at mt etna (italy). Geophysical Journal International, 196(2):633-643, 2014.

K. Cosburn, M. Roy, E. Guardincerri, and C. Rowe. Joint inversion of gravity with cosmic ray muon data at a well-characterized site for shallow subsurface density prediction. Geophysical Journal International, 217(3):1988-2002, 2019 .

S. Dartevelle and G. Valentine. Transient multiphase processes during the explosive eruption of basalt through a geothermal borehole (námafjall, iceland, 1977) and implications for natural volcanic flows. Earth and Planetary Science Letters, 262(3-4):363-384, 2007.

D. E. Dempsey, S. J. Cronin, S. Mei, and A. W. Kempa-Liehr. Automatic precursor recognition and real-time forecasting of sudden explosive volcanic eruptions at Whakaari, New Zealand. Nature Communications, 11:352, 2020. doi: 10.108/s41467-020-17375-2. 
P. Erfurt-Cooper. Active hydrothermal features as tourist attractions. In Observing the Volcano World, pages 85-105. Springer, 2017.

M. Feuillard, C.J. Allegre, G. Brandeis, R. Gaulon, J.-L. Le Mouel, J.-C. Mercier, J.-P. Pozzi, and M. Semet. The 1975-1977 crisis of la soufrière de guadeloupe (fwi): a still-born magmatic eruption. Journal of Volcanology and Geothermal Research, 16(3-4):317-334, 1983.

E. Fujita, K. Araki, and K. Nagano. Volcanic tremor induced by gas-liquid twophase flow: Implications of density wave oscillation. Journal of Geophysical Research: Solid Earth, 116(B9), 2011.

T.K. Gaisser, R. Engel, and E. Resconi. Cosmic rays and particle physics. Cambridge University Press, 2016.

D. Gibert, F. Beauducel, Y. Déclais, N. Lesparre, J. Marteau, F. Nicollin, and A. Tarantola. Muon tomography: Plans for observations in the lesser antilles. Earth, planets and space, 62(2):153-165, 2010.

H. Gómez, D. Gibert, C. Goy, K. Jourde, Y. Karyotakis, S. Katsanevas, J. Marteau, M. Rosas-Carbajal, and A. Tonazzo. Forward scattering effects on muon imaging. Journal of Instrumentation, 12(12):P12018, 2017.

M. Hellweg. Physical models for the source of lascar's harmonic tremor. Journal of Volcanology and Geothermal Research, 101(1-2):183-198, 2000.

T. Johnson, R. Versteeg, A. Ward, F. Day-Lewis, and A. Revil. Improved hydrogeophysical characterization and monitoring through parallel modeling and inversion of time-domain resistivity andinduced-polarization data. Geophysics, 75(4):WA27-WA41, 2010.

G.E. Jolly, H.J.R. Keys, J.N. Procter, and N.I. Deligne. Overview of the co-ordinated risk-based approach to science and management response and recovery for the 2012 eruptions of tongariro volcano, new zealand. Journal of Volcanology and Geothermal Research, 286:184-207, 2014.

K. Jourde, D. Gibert, J. Marteau, J. de Bremond d'Ars, S. Gardien, C. Girerd, J.-C. Ianigro, and D. Carbone. Experimental detection of upward going cosmic particles and consequences for correction of density radiography of volcanoes. Geophysical Research Letters, 40(24):6334-6339, 2013.

K. Jourde, D. Gibert, and J. Marteau. Improvement of density models of geological structures by fusion of gravity data and cosmic muon radiographies. Geoscientific Instrumentation, Methods and Data Systems, 4:177-188, 2015. 
K. Jourde, D. Gibert, J. Marteau, J. de Bremond d'Ars, S. Gardien, C. Girerd, and J.-C. Ianigro. Monitoring temporal opacity fluctuations of large structures with muon radiography: a calibration experiment using a water tower. Scientific reports, 6(1):1-11, 2016a.

K. Jourde, D. Gibert, J. Marteau, J. de Bremond d'Ars, and J.-C. Komorowski. Muon dynamic radiography of density changes induced by hydrothermal activity at the la soufrière of guadeloupe volcano. Scientific reports, 6:33406, 2016b.

S. Kakac and B. Bon. A review of two-phase flow dynamic instabilities in tube boiling systems. International Journal of Heat and Mass Transfer, 51(3-4): 399-433, 2008.

T. Kaneko, F. Maeno, and S. Nakada. 2014 mount ontake eruption: characteristics of the phreatic eruption as inferred from aerial observations. Earth, Planets and Space, 68(1):1-11, 2016.

S.W. Kieffer. Multiphase flow in explosive volcanic and geothermal eruptions. In Theoretical and Applied Mechanics, pages 145-171. Elsevier, 1989.

S. Lane, B. Chouet, J. Phillips, P. Dawson, G. A Ryan, and E. Hurst. Experimental observations of pressure oscillations and flow regimes in an analogue volcanic system. Journal of Geophysical Research: Solid Earth, 106(B4): 6461-6476, 2001.

Y. Le Gonidec, M. Rosas-Carbajal, J. de Bremond d'Ars, B. Carlus, J.-C. Ianigro, B. Kergosien, J. Marteau, and D. Gibert. Abrupt changes of hydrothermal activity in a lava dome detected by combined seismic and muon monitoring. Scientific reports, 9(1):1-9, 2019.

P. Lesage, M.J. Heap, and A. Kushnir. A generic model for the shallow velocity structure of volcanoes. Journal of Volcanology and Geothermal Research, 356:114-126, 2018.

N. Lesparre, D. Gibert, J. Marteau, Y. Déclais, D. Carbone, and E. Galichet. Geophysical muon imaging: feasibility and limits. Geophysical Journal International, 183(3):1348-1361, 2010.

N. Lesparre, J. Marteau, Y. Déclais, D. Gibert, B. Carlus, F. Nicollin, and B. Kergosien. Design and operation of a field telescope for cosmic ray geophysical tomography. Geoscientific Instrumentation Methods and Data Systems, 1(1):47-89, 2011.

N. Lesparre, B. Grychtol, D. Gibert, J.-C. Komorowski, and A. Adler. Crosssection electrical resistance tomography of la soufrière of guadeloupe lava dome. Geophysical Journal International, 197(3):1516-1526, 2014. 
X. Luo, D. Lee, R. Lau, G. Yang, and L.-S. Fan. Maximum stable bubble size and gas holdup in high-pressure slurry bubble columns. AIChE journal, 45 (4):665-680, 1999.

J. Marteau, J. de Bremond d'Ars, D. Gibert, K. Jourde, S. Gardien, C. Girerd, and J.-C. Ianigro. Implementation of sub-nanosecond time-to-digital convertor in field-programmable gate array: applications to time-of-flight analysis in muon radiography. Measurement Science and Technology, 25(3):035101, 2014 .

R. Moretti, J.-C. Komorowski, G. Ucciani, S. Moune, D. Jessop, J.-B. de Chabalier, F. Beauducel, M. Bonifacie, A. Burtin, M. Vallée, S. Deroussi, V. Robert, D. Gibert, T. Didier, T. Kitou, N. Feuillet, P. Allard, G. Tamburello, T. Shreve, J.-. Saurel, A. Lemarchand, M. Rosas-Carbajal, P. Agrinier, A. Le Friant, and M. Chaussidon. The 2018 unrest phase at La Soufrière of Guadeloupe (French West Indies) andesitic volcano: Scrutiny of a failed but prodromal phreatic eruption. Journal of Volcanology and Geothermal Research, 393:106769, mar 2020.

K. Nagamine. Introductory muon science. Cambridge University Press, 2003.

V. Navelot, Y. Géraud, A. Favier, M. Diraison, M. Corsini, J.-M. Lardeaux, C. Verati, J. Mercier de Lépinay, L. Legendre, and G. Beauchamps. Petrophysical properties of volcanic rocks and impacts of hydrothermal alteration in the Guadeloupe Archipelago (West Indies). Journal of Volcanology and Geothermal Research, 360:1-21, jul 2018.

L. Nettleton. Determination of density for reduction of gravimeter observations. Geophysics, 4(3):176-183, 1939.

F. Nicollin, D. Gibert, F. Beauducel, G. Boudon, and J.-C. Komorowski. Electrical tomography of la soufrière of guadeloupe volcano: Field experiments, $1 \mathrm{~d}$ inversion and qualitative interpretation. Earth and Planetary Science Letters, 244(3):709-724, 2006.

R. Nishiyama, Y. Tanaka, S. Okubo, H. Oshima, H.K.M. Tanaka, and T. Maekawa. Integrated processing of muon radiography and gravity anomaly data toward the realization of high-resolution 3-d density structural analysis of volcanoes: Case study of showa-shinzan lava dome, usu, japan. Journal of Geophysical Research: Solid Earth, 119(1):699-710, 2014.

R. Nishiyama, A. Taketa, S. Miyamoto, and K. Kasahara. Monte carlo simulation for background study of geophysical inspection with cosmic-ray muons. Geophysical Journal International, 206(2):1039-1050, 2016. 
T. Oikawa, M. Yoshimoto, S. Nakada, F. Maeno, J. Komori, T. Shimano, Y. Takeshita, Y. Ishizuka, and Y. Ishimine. Reconstruction of the 2014 eruption sequence of ontake volcano from recorded images and interviews. Earth, Planets and Space, 68(1):1-13, 2016.

D.S. Parasnis. A study of rock densities in the english midlands. Geophysical Supplements to the Monthly Notices of the Royal Astronomical Society, 6(5): 252-271, 1952.

G. Phillipson, R. Sobradelo, and J. Gottsmann. Global volcanic unrest in the 21st century: An analysis of the first decade. Journal of Volcanology and Geothermal Research, 264:183-196, 2013.

M. Rosas-Carbajal, J.-C. Komorowski, F. Nicollin, and D. Gibert. Volcano electrical tomography unveils edifice collapse hazard linked to hydrothermal system structure and dynamics. Scientific reports, 6:29899, 2016.

M. Rosas-Carbajal, K. Jourde, J. Marteau, S. Deroussi, J.-C. Komorowski, and D. Gibert. Three-dimensional density structure of la soufrière de guadeloupe lava dome from simultaneous muon radiographies and gravity data. Geophysical Research Letters, 44(13):6743-6751, 2017.

D. Rouwet, L. Sandri, W. Marzocchi, J. Gottsmann, J. Selva, R. Tonini, and P. Papale. Recognizing and tracking volcanic hazards related to nonmagmatic unrest: a review. Journal of Applied Volcanology, 3(1):17, dec 2014 .

Y. Sano, T. Kagoshima, N. Takahata, Y. Nishio, E. Roulleau, D. Pinti, and T. Fischer. Ten-year helium anomaly prior to the $2014 \mathrm{mt}$ ontake eruption. Scientific reports, 5:13069, 2015.

F. Scheck. Muon physics. Physics Reports, 44(4):187-248, 1978.

D. Shanks. Non-linear transformations of divergent and slowly convergent sequences. Journal of Mathematics and Physics, 34(1-4):1-42, 1955.

I. A Sokalski, E. V Bugaev, and S.I. Klimushin. Mum: flexible precise monte carlo algorithm for muon propagation through thick layers of matter. Physical Review D, 64(7):074015, 2001.

D. Sornette. Critical phenomena in natural sciences: chaos, fractals, selforganization and disorder: concepts and tools. Springer Science \& Business Media, 2006.

D. Sornette and W.-X. Zhou. The US 2000-2002 market descent: How much longer and deeper? Quantitative Finance, 2(6):468-481, 2002. 
H.K.M. Tanaka, T. Nakano, S. Takahashi, J. Yoshida, M. Takeo, J. Oikawa, T. Ohminato, Y. Aoki, E. Koyama, H. Tsuji, et al. High resolution imaging in the inhomogeneous crust with cosmic-ray muon radiography: The density structure below the volcanic crater floor of mt. asama, japan. Earth and Planetary Science Letters, 263(1-2):104-113, 2007.

H.K.M. Tanaka, T. Uchida, M. Tanaka, H. Shinohara, and H. Taira. Cosmicray muon imaging of magma in a conduit: Degassing process of satsumaiwojima volcano, japan. Geophysical Research Letters, 36(1), 2009a.

H.K.M. Tanaka, T. Uchida, M. Tanaka, M. Takeo, J. Oikawa, T. Ohminato, Y. Aoki, E. Koyama, and H. Tsuji. Detecting a mass change inside a volcano by cosmic-ray muon radiography (muography): First results from measurements at asama volcano, japan. Geophysical Research Letters, 36(17), 2009b.

H.K.M. Tanaka, H. Taira, T. Uchida, M. Tanaka, M. Takeo, T. Ohminato, Y. Aoki, R. Nishitama, D. Shoji, and H. Tsuiji. Three-dimensional computational axial tomography scan of a volcano with cosmic ray muon radiography. Journal of Geophysical Research: Solid Earth, 115(B12), 2010.

R. Tonini, L. Sandri, D. Rouwet, C. Caudron, W. Marzocchi, et al. A new bayesian event tree tool to track and quantify volcanic unrest and its application to kawah ijen volcano. Geochemistry, Geophysics, Geosystems, 17(7): 2539-2555, 2016.

B. Villemant, J.-C. Komorowski, C. Dessert, A. Michel, O. Crispi, G. Hammouya, F. Beauducel, and J.-B. de Chabalier. Evidence for a new shallow magma intrusion at la soufrière of guadeloupe (lesser antilles): insights from long-term geochemical monitoring of halogen-rich hydrothermal fluids. Journal of Volcanology and Geothermal Research, 285:247-277, 2014.

E. Zimmermann, A. Kemna, J. Berwix, W. Glaas, and H. Vereecken. EIT measurement system with high phase accuracy for the imaging of spectral induced polarization properties of soils and sediments. Measurement Science and Technology, 19(9):094010, 2008. 